\title{
Adolescents' perceived barriers to accessing sexual and reproductive health services in California: a cross-sectional survey
}

Martha J. Decker ${ }^{1,2,3^{*}}$, Tara V. Atyam ${ }^{4}$, Catherine Gilmore Zárate ${ }^{4}$, Angela M. Bayer ${ }^{4}$, Consuelo Bautista ${ }^{4}$ and Melissa Saphir ${ }^{2}$

\begin{abstract}
Background: Adolescents may forego needed sexual and reproductive health (SRH) services due to a variety of concerns and barriers. The purpose of this study is to compare adolescents' perceptions of these barriers by participant characteristics including race/ethnicity, gender, sexual orientation, housing situation, and sexual experience.

Methods: Adolescents in a California-wide sexual health education program completed an anonymous survey at baseline $(N=10,015)$ about perceived barriers to using SRH services. Logistic regression analyses that accounted for the clustered data structure assessed differences by gender, age, sexual orientation, race/ethnicity, living situation, and sexual experience.

Results: The majority of participants were Hispanic/Latino (76.4\%) with an average age of 14.9 years, and 28.8\% had sexual experience. Half of the youth reported concerns about test results (52.7\%), cost of services (52.0\%), and confidentiality of services (49.8\%). When controlling for other characteristics, youth identifying as transgender/non-binary/ multiple genders had the highest odds of perceiving cost (odds ratio (OR) 1.89) and confidentiality (OR 1.51) as barriers. Increasing age was associated with decreasing odds of all barriers. Sexual orientation was a consistent predictor, with $L G B Q+$ youth having higher odds of perceiving test results (OR 1.21), cost (OR 1.36), and confidentiality (OR 1.24) as barriers. Asian or Pacific Islander/Native Hawaiian youth had higher odds of perceiving test results (OR 1.68) and cost (OR 1.37) as barriers. In contrast, Black youth had lower odds of reporting cost (OR 0.65) and confidentiality (OR 0.77) as barriers. Younger respondents and youth who identified as female, transgender/non-binary/multiple genders, $\mathrm{LGBQ}+$, and Asian or Pacific Islander/Native Hawaiian had higher odds of reporting five or more barriers compared to reference groups.
\end{abstract}

Conclusions: The majority of adolescents face barriers to accessing appropriate SRH services, with females, genderminority youth, younger adolescents, LGBQ+ youth, and Asian and Pacific Islander/Native Hawaiian youth more likely than others to report barriers. Access to SRH services can be improved through strengthening linkages between clinics and SRH education programs, providing youth-friendly clinical services, and ensuring youth have sufficient information, skills, and support to access care.

Trial registration: Approved by California Health and Human Services Agency's Committee for the Protection of Human Subjects [12-08-0658, 11/30/2017].

\footnotetext{
*Correspondence: mara.decker@ucsf.edu

2 Philip R. Lee Institute for Health Policy Studies, University of California,

San Francisco, 490 Illinois St, San Francisco, CA 94107, USA

Full list of author information is available at the end of the article
} original author(s) and the source, provide a link to the Creative Commons licence, and indicate if changes were made. The images or other third party material in this article are included in the article's Creative Commons licence, unless indicated otherwise in a credit line to the material. If material is not included in the article's Creative Commons licence and your intended use is not permitted by statutory regulation or exceeds the permitted use, you will need to obtain permission directly from the copyright holder. To view a copy of this licence, visit http://creativecommons.org/licenses/by/4.0/. The Creative Commons Public Domain Dedication waiver (http://creativeco mmons.org/publicdomain/zero/1.0/) applies to the data made available in this article, unless otherwise stated in a credit line to the data. 
Keywords: Adolescents, Sexual health, Sex education, Reproductive health services, California, Barriers to care, Burden of barriers, Confidentiality

\section{Background}

Adolescents may forego needed sexual and reproductive health $(\mathrm{SRH})$ services due to a variety of concerns and barriers. Previous research has identified common barriers to SRH services among adolescents that include confidentiality, stigma, embarrassment, and fear $[1,2]$. Structural challenges such as cost, location, transportation, and limited scheduling also may reduce adolescents' access to services [3]. Additionally, adolescents often cite unfriendly or judgmental interactions or distrust of providers as a reason for not seeking sexual health services $[4,5]$.

Certain groups of adolescents face greater barriers to accessing services than others, with disparities in access based on gender, race and ethnicity, and sexual orientation, among other characteristics. While concerns about confidentiality and embarrassment are common across youth of all genders and backgrounds, one study found that female youth who were concerned about confidentiality, particularly related to their parents, were less likely to receive contraceptive services [6]. A qualitative study of young men identified a range of challenges, including the perception that SRH services were not designed for them [7]. Studies of lesbian, gay, bisexual, transgender, and queer (LGBTQ) youth have found respectful providers to be a priority and that transgender youth were more likely to postpone or not get care due to provider discrimination $[8,9]$. One large survey of female youth found that sexual minority females were less likely to access routine screenings such as sexually transmitted infection (STI) testing and Pap smears, although bisexual females were significantly more likely to have had a positive STI test compared to heterosexuals or lesbians [10]. Similarly, sexual minority females are more likely to become pregnant during adolescence than heterosexual females [11].

Youth of certain racial and ethnic backgrounds also experience disparities in access as well as concerns about stigma and discrimination $[1,12]$. Prior research of gendered racism, discrimination at the intersection of race/ ethnicity and gender, has recognized the impact of contraceptive mistrust and stereotypes regarding sexual and reproductive behaviors among Black and Latina women [13]. One qualitative study of Latina youth identified barriers at the sociocultural, relational, and individual levels, with the most common being parental attitudes toward SRH access [14]. Little research has focused on other racial and ethnic groups, including Asian Americans and
Native Americans. A quantitative analysis found that Native Americans at every age, including adolescence, were less likely to use contraceptive services than White women, but more likely to use services for HIV and STIs [15]. One qualitative study of Asian American young women recognized concerns about confidentiality and cultural stigma as barriers to using SRH services [16]. The intersection of these different demographic characteristics may also amplify concerns among certain groups. For example, Latino youth living in rural areas often worry about privacy due to small and tight-knit communities and have limited services available [17].

Youth in vulnerable or unstable living situations may face additional barriers to accessing SRH services including a lack of a regular healthcare provider and unfamiliarity with local services. One survey of homeless and runaway youth found that transportation, cost, and lack of insurance were common barriers to seeking healthcare services [18]. One small qualitative study of youth leaving foster care found that confidentiality concerns related to their foster parents limited their interaction and communication regarding SRH needs with their healthcare providers [19].

These barriers to SRH care perceived by adolescents fall into five key domains that Penchansky and Thomas identified as affecting access to health care: affordability, availability, accessibility, accommodation, and acceptability [20]. While these domains represent essential structural and individual considerations, it is also important to examine how experiencing multiple barriers affects youth. To date, minimal research has evaluated the impact of multiple barriers on youth when accessing SRH services. One study of women accessing abortion care found that experience of multiple barriers can have a compounding effect, resulting in negative consequences for the patient [21]. The burden of these barriers may be interconnected and cyclical. A secondary analysis of a survey of adults conducted in 11 countries including the United States found that vulnerable groups are more likely to experience multiple barriers in accessing care [22]. The cumulative result of multiple barriers and the related disparities in access has not been assessed among adolescents.

While there have been studies of barriers to adolescent access to SRH services in other countries, the majority of studies in the United States have been qualitative, with small samples drawn from a specific population of interest [23-25]. Few have compared these barriers across different populations or assessed which populations 
have the highest burden of barriers. This study builds on Penchansky and Tomas's theory of access by specifically incorporating a health disparities and equity lens [26]. The purpose of this study is to quantitatively assess adolescents' perceptions of barriers to accessing SRH services by demographic and behavioral characteristics prior to receiving sexual health education.

\section{Methods}

\section{Program setting}

All participants in California's Personal Responsibility Education Program (CA PREP) were asked to complete a baseline survey at program entry. This program is a federally funded initiative administered through the California Department of Public Health's Maternal, Child and Adolescent Health Division. CA PREP aims to reduce unintended pregnancy and STIs among California's adolescents by providing them with comprehensive, medically accurate, and unbiased SRH education, in compliance with the 2016 California Healthy Youth Act [27]. Twenty-two agencies serving 20 high-need counties encompassing urban, suburban, and rural areas across California implemented the program in 2018-2019 using one of four evidence-based curricula [28]. Program eligibility is based on several county-level indicators including, but not limited to, adolescent birth rate, percentage of adolescent repeat births, gonorrhea index rate, and percentage of youth living in concentrated poverty and/or racially isolated areas [29]. Program delivery is prioritized for vulnerable youth, such as those in foster care and juvenile justice systems, migrant youth, homeless and runaway youth, youth with special needs, and LGBTQ youth. A majority of program recipients are Latino, reflecting the fact that the majority of school-aged children (55\%) in California are Latino, with higher percentages in the southern part of the state [30]. PREP serves youth in more than 300 unique sites, including traditional high schools, alternative or continuation schools, shelters and transitional housing, middle schools, juvenile justice facilities, community-based organizations, foster care and clinics.

\section{Participants and procedures}

Confidential paper surveys, in English and Spanish, were administered by trained facilitators from implementing agencies to youth at the beginning of the program. Prior to the survey, all participants completed an assent/consent form. In addition, passive parental or guardian consent, meaning parents or guardians needed to sign and return the consent form for refusal, was used per state guidelines for sexual health education [27]. Between July 1, 2018 and June 30, 2019, 13,564 youth participated in the program and 10,558 completed the voluntary, anonymous survey $(77.8 \%)$. Youth ages 20 and 21 or older ( $n$ $=93$ ) and those who skipped the barriers questions ( $n$ $=450$ ) were dropped from the analysis for a final sample size of 10,015 adolescents. The 22-question survey was approved by the Committee for the Protection of Human Subjects [12-08-0658] of the California Health and Human Services Agency.

\section{Dependent variables: perceived barriers}

Measures were based on Penchansky and Tomas's dimensions of access to health care [20,31] and refined to reflect prior research on adolescent barriers to SRH services (Table 1). Although the original theory did not include awareness as a dimension, subsequent research has recommended this addition [32]. Similarly, concern

Table 1 Dimensions of access to care

Penchanksy and Thomas's dimensions of access
Availability: volume and type of services to meet the clients' needs
Accessibility: location of the services and how easily the clients can reach
the location, including cost and travel time
Accommodation: how services are organized (including appointment
systems, telephone services) and the clients' perception of their appropri-
ateness

Affordability: the prices of services and insurance requirements compared to the clients' ability to pay

Acceptability: clients' preferences for the personal characteristics and attitudes of providers

Awareness: client knowledge and awareness of existing services through effective communication and information strategies

\section{Survey item}

Lack of access: It would be easy for me to go to a clinic ${ }^{1}$

Confidentiality of services: I would be worried about getting sexual health services because my parents/guardians, family, sexual partner, or friends may find out

Test results: I would be worried about test results

Cost of service: I would be worried about cost

Judgment by staff: I would be worried that clinic staff may judge or disrespect me

Discomfort talking with staff: I would feel comfortable talking with clinic staff about my sexual health and questions 
about test results was added as a barrier in the accommodation dimension based on previous research $[11,33]$. Prior to implementation, the survey was pilot tested with youth and health educators, and wording was revised as needed.

A previous question in the survey defined sexual health services as "a clinic or doctor in your community where teens can get sexual health information and services (such as condoms, birth control, pregnancy tests, and STI and HIV tests)". Responses to four questions (about test results, cost, confidentiality, and judgment) were coded as follows: "agree" and "strongly agree" were coded 1 , and "disagree" and "strongly disagree" were coded 0. Responses to three questions (about comfort talking to clinic staff, knowledge, and access) were reverse-coded, so that all questions represent a barrier to SRH clinic services: "disagree" and "strongly disagree" were coded 1 and "agree" and "strongly agree" were coded 0.

To operationalize burden of barriers, we first summed the seven dichotomous variables described above and examined the distribution of the resulting sum. A sharp drop-off in the distribution was observed at five perceived barriers, with only $10.0 \%$ perceiving five barriers and only $7.0 \%$ perceiving six or seven barriers. Because we were interested in severe burden of barriers, we transformed the sum into a dichotomous variable with five as the cutpoint. Participants who perceived five, six, or seven barriers were coded 1 (high burden of barriers,) and all others were coded 0 (low burden of barriers).

\section{Independent variables: participant characteristics \\ Gender}

Respondents were asked to mark all gender responses that apply. Responses were coded as male, female, and transgender/non-binary/multiple genders.

\section{Age}

Respondents were asked to mark their ages from 10 to 21 years or older. Youth ages 20 and older were removed from the analysis. Age was entered as a continuous variable in the regression analyses.

\section{Sexual orientation}

Respondents were asked to mark all sexual orientation categories that apply. Responses were coded as straight/ heterosexual or LGBQ+. The LGBQ+ category included "Gay," "Lesbian," "Bisexual," "Queer," "Questioning," "Other," and multiple responses.

\section{Ethnicity and race}

For ethnicity, respondents were asked "Are you Hispanic or Latino?" For race, respondents were asked to mark all race categories that apply. Response options were
"White," "Black or African American," "Asian," "Native Hawaiian or Pacific Islander," and "American Indian or Alaska Native." Due to small numbers, "Asian" and "Native Hawaiian or Pacific Islander" responses were combined into one category, Asian or Pacific Islander/ Native Hawaiian. Almost half (46\%) of the participants declined to provide a race category. Of these, $96 \%$ identified as Hispanic; therefore, ethnicity and race responses were combined for the multivariate analysis. Those who said they were "Hispanic or Latino" were coded as Hispanic, regardless of any race they marked. Among those who were not Hispanic or Latino, those who marked a single race were coded as that race, while those who marked multiple races were coded as multiple.

\section{Living situation}

From a list of seven living situations, respondents were asked to select all that describe where they currently live. "In foster care, living with a family" and "In foster care, living in a group home" were coded as being in foster care. "In juvenile detention, jail, prison, or another correction facility, or under the supervision of a probation officer" was coded as juvenile justice facility. "Couch surfing or moving from house to house", "Living in a place not meant to be a residence", and "Staying in an emergency shelter, transitional living program, or motel" were coded as unstable housing. Respondents who did not mark any of the options provided were coded as having stable housing.

\section{Sexual experience}

Respondents were asked two questions about their sexual experience: "Have you ever had vaginal sex (penis in vagina)?" and "Have you ever had anal sex (penis in butt)?" Those who responded "Yes" to either or both of these questions were coded as having ever had vaginal and/or anal sex. All others were coded no.

\section{Analysis}

To understand how youth differed in perception of barriers to SRH services, we first examined the dependent variables within each participant characteristic at baseline using one-way ANOVA with Bonferroni adjustment for multiple comparisons. Next, we conducted logistic regressions to calculate odds ratios for each participant subgroup while controlling for other demographic variables and sexual experience. We used the melogit command in Stata version 16 [31] to account for the nonindependence of data collected from students clustered within cohorts and cohorts clustered within agencies [34]. In all analyses, $p$ values of 0.05 or less were considered statistically significant. 


\section{Results}

\section{Participant characteristics}

There were slightly more male $(51.9 \%)$ than female respondents $(46.8 \%)$, with $1.3 \%$ of youth identifying as transgender or non-binary or selecting multiple responses (Table 2). The sample was fairly evenly split between 10 - to 14 -year-olds (46.0\%) and 15- to 19-yearolds (54.0\%). The majority of participants identified as straight or heterosexual (84.4\%), and $15.6 \%$ identified with LGBQ+ sexual orientations. The majority of participants identified as Hispanic or Latino ethnicity (76.4\%), and the majority of these youth did not report their race. Among all participants, $46.1 \%$ did not identify a race, 25.9\% identified as white, $8.2 \%$ as American Indian/ Alaska Native, $7.7 \%$ as Black, $6.0 \%$ as Asian or Pacific

Table 2 Participant characteristics

\begin{tabular}{|c|c|c|}
\hline & $\begin{array}{l}\text { Total } \\
(N=10,015)\end{array}$ & Percent \\
\hline \multicolumn{3}{|l|}{ Gender } \\
\hline Male & 5,166 & 51.9 \\
\hline Female & 4,664 & 46.8 \\
\hline Transgender/non-binary/multiple genders & 129 & 1.3 \\
\hline \multicolumn{3}{|l|}{ Age } \\
\hline 10- 14 years & 4,579 & 46.0 \\
\hline 15-19 years & 5,369 & 54.0 \\
\hline \multicolumn{3}{|l|}{ Sexual orientation } \\
\hline Straight/heterosexual & 8,140 & 84.4 \\
\hline Bisexual & 666 & 6.9 \\
\hline Questioning & 200 & 2.1 \\
\hline Gay/lesbian & 179 & 1.9 \\
\hline Multiple/queer/other & 458 & 4.8 \\
\hline \multicolumn{3}{|l|}{ Ethnicity } \\
\hline Hispanic & 7,546 & 76.4 \\
\hline Non-Hispanic & 2,328 & 23.6 \\
\hline \multicolumn{3}{|l|}{ Race } \\
\hline White & 2,590 & 25.9 \\
\hline American Indian/Alaska Native & 822 & 8.2 \\
\hline Black & 766 & 7.7 \\
\hline Asian or Pacific Islander/Native Hawaiian & 605 & 6.0 \\
\hline Multiple & 619 & 6.2 \\
\hline Missing & 4,613 & 46.1 \\
\hline \multicolumn{3}{|l|}{ Living situation } \\
\hline Stable housing & 8,585 & 88.2 \\
\hline Foster care & 591 & 6.1 \\
\hline Juvenile justice facility & 357 & 3.7 \\
\hline Unstable housing & 201 & 2.1 \\
\hline \multicolumn{3}{|l|}{ Ever had vaginal and/or anal sex } \\
\hline No & 7,039 & 71.2 \\
\hline Yes & 2,851 & 28.8 \\
\hline
\end{tabular}

Note: Except for race, percentages are based on those with non-missing data
Islander/Native Hawaiian, and $6.2 \%$ as multiple races. The majority $(88.2 \%)$ reported living in stable housing. Much smaller percentages reported living in foster care (6.1\%), juvenile justice facilities (3.7\%), or an unstable housing situation (2.1\%). Most participants (71.2\%) had never had vaginal and/or anal sex. Youth with sexual experience tended to be older $(43.7 \%$ of 15 - to 19 -yearolds were sexually active, compared to $11.4 \%$ of 10 - to 14-year-olds) and male (34.9\% of males were sexually active, compared to $22.2 \%$ of females and $28.8 \%$ of youth identifying as transgender, non-binary or multiple genders). Over half of youth (56.3\%) had heard of a clinic where SRH services are provided.

\section{Perceived barriers}

Table 3 shows perceptions of each barrier and burden of five or more barriers in the sample as a whole, and differences in perceptions by participant characteristics. About half of the youth reported concerns about test results $(52.7 \%)$, cost $(52.0 \%)$, and confidentiality (49.8\%). Two other common barriers were related to interacting with providers, including discomfort talking with staff about sexual health (36.7\%) and worrying about being judged by staff (36.4\%). Youth were less likely to report lack of knowledge about the visit $(29.1 \%)$ and lack of access $(26.3 \%)$ as barriers to SRH services. Almost one fifth of youth (17.8\%) reported five or more barriers.

Youth of different gender identities, sexual orientation, and age groups consistently had differences in perceptions of barriers. Compared to male youth, female youth were significantly more likely to perceive every barrier and five or more barriers (Fig. 1). Similarly, youth identifying as transgender, non-binary, or with multiple genders were significantly more likely than male youth to report five or more barriers and every barrier except worry about test results and not knowing what to expect during a clinic visit. Compared to heterosexual youth, LGBQ+ youth were more likely to perceive every barrier except discomfort talking with staff. Younger youth were significantly more likely than older youth to perceive every barrier and five or more barriers. Figure 2 illustrates the decline in burden of five or more barriers by age.

Reported barriers were more mixed across categories of ethnicity/race. Because the majority of our sample identified as Hispanic or Latino, perceptions of barriers for this group closely mirror the percentages already reported for the sample as a whole. That is, over half of Hispanic youth reported concern about test results, cost of service, and confidentiality, and almost onefifth reported five or more barriers. Hispanic youth were more likely to report cost of service and confidentiality as barriers, and less likely to report discomfort 
Table 3 Percent of participants who perceive given barriers to accessing sexual and reproductive health services

\begin{tabular}{|c|c|c|c|c|c|c|c|c|c|}
\hline & $\begin{array}{l}\text { Group } \\
\mathrm{n}\end{array}$ & Test results & $\begin{array}{l}\text { Cost of } \\
\text { service }\end{array}$ & $\begin{array}{l}\text { Confidentiality } \\
\text { of service }\end{array}$ & $\begin{array}{l}\text { Discomfort } \\
\text { talking with } \\
\text { staff }\end{array}$ & $\begin{array}{l}\text { Judgment by } \\
\text { staff }\end{array}$ & $\begin{array}{l}\text { Lack of } \\
\text { knowledge } \\
\text { about visit }\end{array}$ & $\begin{array}{l}\text { Lack of } \\
\text { access }\end{array}$ & $\begin{array}{l}5 \text { or } \\
\text { moreBarriers }\end{array}$ \\
\hline $\begin{array}{l}\text { All partici- } \\
\text { pants }\end{array}$ & 10,015 & 52.7 & 52.0 & 49.8 & 36.7 & 36.4 & 29.1 & 26.3 & 17.8 \\
\hline \multicolumn{10}{|l|}{ Gender } \\
\hline $\begin{array}{l}\text { Male (refer- } \\
\text { ence) }\end{array}$ & 5,166 & 51.1 & 49.4 & 43.9 & 35.1 & 30.1 & 27.1 & 22.5 & 13.3 \\
\hline Female & 4,664 & $54.5^{* *}$ & $54.4^{* * *}$ & $56.1^{* * *}$ & $37.9^{*}$ & $42.8^{* * *}$ & $31.1^{* * *}$ & $29.8^{* * *}$ & $22.3^{* * *}$ \\
\hline $\begin{array}{l}\text { Transgen- } \\
\text { der/non- } \\
\text { binary/multi- } \\
\text { ple genders }\end{array}$ & 129 & 53.9 & $68.8^{* * *}$ & $59.2^{* *}$ & $49.2^{* *}$ & $53.5^{* * *}$ & 34.1 & $42.5^{* * *}$ & $32.6^{* * *}$ \\
\hline \multicolumn{10}{|l|}{ Age } \\
\hline $\begin{array}{l}\text { 10-14 years } \\
\text { (reference) }\end{array}$ & 4,579 & 56.3 & 54.9 & 53.8 & 43.8 & 40.2 & 33.9 & 30.8 & 21.8 \\
\hline $15-19$ years & 5,369 & $49.6^{* * *}$ & $49.4^{* * *}$ & $46.4^{* * *}$ & $30.6^{* * *}$ & $33.2^{* * *}$ & $24.9^{* * *}$ & $22.4^{* * *}$ & $14.5^{* * *}$ \\
\hline \multicolumn{10}{|c|}{ Sexual orientation } \\
\hline $\begin{array}{l}\text { Straight/ } \\
\text { heterosexual } \\
\text { (reference) }\end{array}$ & 8,140 & 51.9 & 50.7 & 48.7 & 36.3 & 34.8 & 28.5 & 25.3 & 16.6 \\
\hline LGBQ+ & 1,503 & $57.0^{* * *}$ & $59.2^{* * *}$ & $56.7^{* * *}$ & 37.5 & $44.7^{* * *}$ & $31.1^{*}$ & $31.0^{* * *}$ & $25.1^{* * *}$ \\
\hline \multicolumn{10}{|l|}{ Ethnicity/race } \\
\hline $\begin{array}{c}\text { Hispanic } \\
\text { (reference) }\end{array}$ & 7,546 & 53.0 & 52.6 & 50.6 & 35.9 & 36.7 & 27.9 & 25.8 & 17.6 \\
\hline $\begin{array}{l}\text { Non-His- } \\
\text { panic White }\end{array}$ & 968 & $46.8^{* *}$ & 51.3 & 46.5 & $41.2^{*}$ & 36.0 & $34.4^{* *}$ & 29.7 & 19.1 \\
\hline $\begin{array}{l}\text { Non-His- } \\
\text { panic Black }\end{array}$ & 479 & 47.8 & $39.5^{* * *}$ & $40.9^{* *}$ & 30.8 & $28.9^{*}$ & 23.5 & $18.3^{* *}$ & $11.1^{* *}$ \\
\hline $\begin{array}{l}\quad \text { Non- } \\
\text { Hispanic Asian } \\
\text { or Pacific } \\
\text { Islander/ } \\
\text { Native Hawai- } \\
\text { ian }\end{array}$ & 407 & $65.8^{* * *}$ & $62.4^{* *}$ & 54.9 & $44.0^{*}$ & $44.4^{*}$ & $38.4^{* * *}$ & 32.3 & $29.7^{* * *}$ \\
\hline $\begin{array}{l}\quad \text { Non- } \\
\text { Hispanic } \\
\text { American } \\
\text { Indian/ Alaska } \\
\text { Native }\end{array}$ & 133 & 58.6 & 44.6 & 42.9 & 42.3 & 40.5 & 36.4 & 32.8 & 17.3 \\
\hline $\begin{array}{c}\text { Non-His- } \\
\text { panic Multiple }\end{array}$ & 331 & 52.6 & 45.8 & 48.1 & 33.5 & 29.5 & 29.4 & 27.2 & 13.9 \\
\hline \multicolumn{10}{|c|}{ Living situation } \\
\hline $\begin{array}{c}\text { Stable } \\
\text { housing } \\
\text { (reference) }\end{array}$ & 8,585 & 52.6 & 53.0 & 51.3 & 37.0 & 36.9 & 29.5 & 26.8 & 18.5 \\
\hline Foster care & 591 & 57.5 & 50.9 & 46.7 & 34.8 & 37.5 & 24.6 & 25.3 & 15.9 \\
\hline $\begin{array}{l}\text { Juvenile } \\
\text { justice facility }\end{array}$ & 357 & $43.2^{* *}$ & $31.0^{* * *}$ & $22.5^{* * *}$ & $22.8^{* * *}$ & $19.9^{* * *}$ & $22.1^{*}$ & $11.0^{* * *}$ & $5.6^{* * *}$ \\
\hline $\begin{array}{l}\text { Unstable } \\
\text { housing }\end{array}$ & 224 & 53.4 & 55.9 & 47.5 & 42.0 & 45.9 & 31.4 & 31.7 & 17.4 \\
\hline \multicolumn{10}{|c|}{ Ever had vaginal and/or anal sex } \\
\hline $\begin{array}{l}\text { No (refer- } \\
\text { ence) }\end{array}$ & 7,039 & 54.8 & 55.0 & 53.1 & 40.5 & 38.7 & 31.8 & 28.7 & 20.3 \\
\hline Yes & 2,851 & $47.9^{* * *}$ & $44.7^{* * *}$ & $41.9^{* * *}$ & $26.5^{* * *}$ & $30.7^{* * *}$ & $22.5^{* * *}$ & $20.0^{* * *}$ & $11.8^{* * *}$ \\
\hline
\end{tabular}



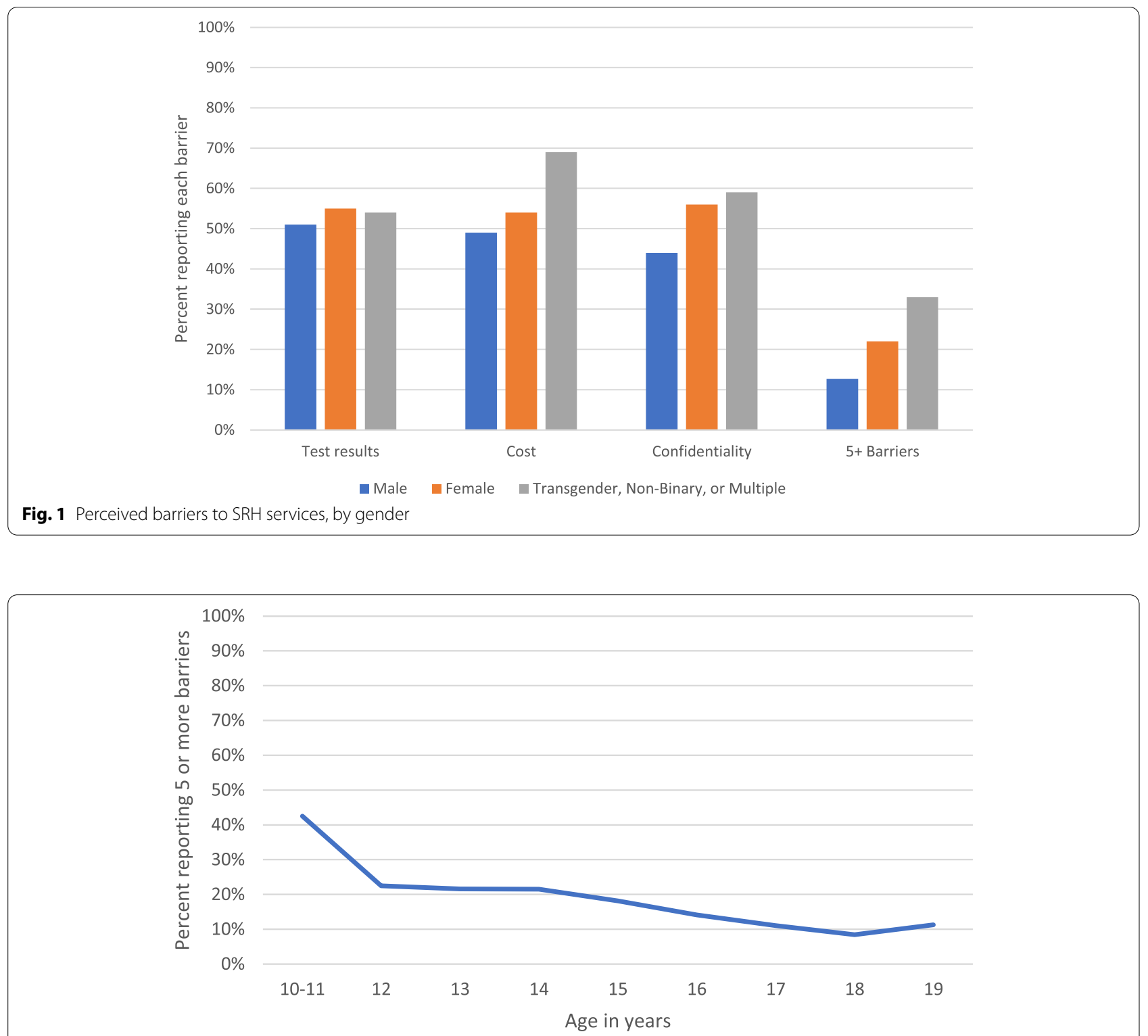

Fig. 2 Burden of five or more barriers, by age

talking with staff and not knowing what to expect in a clinic visit compared to Non-Hispanic youth (data not shown). Asian or Pacific Islander/Native Hawaiian youth were the only group to have consistently higher percentages reporting barriers than the Hispanic reference group. Black youth were the only group to have consistently lower percentages reporting barriers than the Hispanic reference group. Youth living in juvenile justice facilities were also less likely to report all barriers, including five or more barriers, compared to youth living in stable housing. This pattern was also similar for those who reported having vaginal and/or anal sex, as they were less likely to report all barriers as well as for five or more barriers compared to youth who did not have vaginal and/or anal sex (see Table 3 ).

\section{Participant characteristics and perceived barriers}

Results for logistic regressions of all the participant characteristics on the three most common barriers and for five or more barriers are shown in Table 4. When controlling for all other participant characteristics, females and youth identifying as transgender/non-binary/multiple genders had higher odds of perceiving cost of service and confidentiality of service as barriers as well as five or more barriers, with 1.10-1.68 times the odds for females and 1.51-2.38 times the odds for youth identifying as 
Table 4 Predictors of perceiving barriers to sexual and reproductive health services

\begin{tabular}{|c|c|c|c|c|c|c|c|c|}
\hline & \multicolumn{2}{|l|}{$\begin{array}{l}\text { Test results } \\
(N=9,008)\end{array}$} & \multicolumn{2}{|l|}{$\begin{array}{l}\text { Cost of service } \\
(N=9,036)\end{array}$} & \multicolumn{2}{|c|}{$\begin{array}{l}\text { Confidentiality of } \\
\text { service } \\
(N=9,013)\end{array}$} & \multicolumn{2}{|c|}{$\begin{array}{l}5 \text { or more barriers } \\
(N=9,167)\end{array}$} \\
\hline & OR $(95 \% \mathrm{Cl})$ & $p$ & OR $(95 \% \mathrm{Cl})$ & $p$ & OR $(95 \% \mathrm{CI})$ & $p$ & OR $(95 \% \mathrm{Cl})$ & $p$ \\
\hline \multicolumn{9}{|l|}{ Gender } \\
\hline Male & Reference & - & Reference & - & Reference & - & Reference & - \\
\hline Female & $1.05(0.96,1.15)$ & 0.266 & $1.10(1.00,1.20)$ & 0.045 & $1.48(1.35,1.61)$ & $<0.001$ & $1.68(1.49,1.88)$ & $<0.001$ \\
\hline Transgender/non-binary/multiple genders & $0.82(0.56,1.21)$ & 0.316 & $1.89(1.24,2.88)$ & 0.003 & $1.51(1.01,2.24)$ & 0.044 & $2.38(1.55,3.63)$ & $<0.001$ \\
\hline Age (continuous) & $0.90(0.87,0.93)$ & $<0.001$ & $0.96(0.93,0.99)$ & 0.016 & $0.90(0.87,0.93)$ & $<0.001$ & $0.84(0.81,0.88)$ & $<0.001$ \\
\hline \multicolumn{9}{|l|}{ Sexual orientation } \\
\hline Straight/heterosexual & Reference & - & Reference & - & Reference & - & Reference & - \\
\hline LGBQ+ & $1.21(1.07,1.37)$ & 0.002 & $1.36(1.20,1.54)$ & $<0.001$ & $1.24(1.10,1.41)$ & 0.001 & $1.42(1.22,1.64)$ & $<0.001$ \\
\hline \multicolumn{9}{|l|}{ Ethnicity/race } \\
\hline Hispanic & Reference & - & Reference & - & Reference & - & Reference & - \\
\hline Non-Hispanic & - & - & - & - & - & - & - & - \\
\hline White & $0.76(0.65,0.88)$ & $<0.001$ & $0.91(0.78,1.06)$ & 0.238 & $0.82(0.70,0.96)$ & 0.012 & $1.01(0.83,1.23)$ & 0.899 \\
\hline Black & $0.88(0.72,1.08)$ & 0.224 & $0.65(0.53,0.81)$ & $<0.001$ & $0.77(0.62,0.95)$ & 0.015 & $0.66(0.48,0.90)$ & 0.009 \\
\hline Asian/Pacific Islander/ Native Hawaiian & $1.68(1.34,2.11)$ & $<0.001$ & $1.37(1.09,1.72)$ & 0.006 & $1.14(0.91,1.42)$ & 0.262 & $1.82(1.42,2.33)$ & $<0.001$ \\
\hline American Indian/Alaska Native & $1.28(0.87,1.89)$ & 0.213 & $0.76(0.52,1.12)$ & 0.167 & $0.73(0.50,1.08)$ & 0.119 & $1.02(0.62,1.68)$ & 0.930 \\
\hline Multiple & $1.01(0.79,1.28)$ & 0.954 & $0.75(0.59,0.95)$ & 0.018 & $0.93(0.73,1.18)$ & 0.547 & $0.69(0.49,0.98)$ & 0.036 \\
\hline \multicolumn{9}{|l|}{ Living situation } \\
\hline Stable housing & Reference & - & Reference & - & Reference & - & Reference & - \\
\hline Foster care & $1.27(1.05,1.53)$ & 0.013 & $1.02(0.84,1.23)$ & 0.854 & $0.92(0.76,1.11)$ & 0.378 & $0.85(0.66,1.10)$ & 0.210 \\
\hline Juvenile justice facility & $0.87(0.68,1.11)$ & 0.260 & $0.58(0.45,0.76)$ & $<0.001$ & $0.42(0.32,0.55)$ & $<0.001$ & $0.47(0.29,0.76)$ & 0.002 \\
\hline Unstable housing & $1.13(0.83,1.53)$ & 0.430 & $1.41(1.04,1.91)$ & 0.027 & $1.12(0.83,1.52)$ & 0.450 & $1.06(0.71,1.58)$ & 0.768 \\
\hline \multicolumn{9}{|l|}{ Ever had vaginal and/or anal sex } \\
\hline No & Reference & - & Reference & - & Reference & - & Reference & - \\
\hline Yes & $0.93(0.84,1.04)$ & 0.216 & $0.80(0.71,0.89)$ & $<0.001$ & $0.91(0.82,1.02)$ & 0.101 & $0.78(0.67,0.91)$ & 0.001 \\
\hline
\end{tabular}

Note: Odds ratios are based on mixed-effects logit models, accounting for the nested structure of the data (participants within cohorts and cohorts within agencies)

transgender/non-binary/multiple genders compared to males.

Older youth had lower odds of perceiving any of the barriers, including five or more barriers, compared to younger participants. For every year of increase in age, there was a 0.04-0.16 decrease in odds of reporting test results, cost, and confidentiality as barriers and five or more barriers. Youth identifying as LGBQ+ had 1.211.42 times the odds of reporting test results, cost, and confidentiality as barriers as well as five or more barriers, relative to heterosexual youth.

Compared to Hispanic youth, Asian or Pacific Islander/ Native Hawaiian youth had 1.37-1.80 times the odds of perceiving test results and cost as barriers as well as perceiving five or more barriers. In contrast, Black youth had 0.65-0.77 times the odds of perceiving cost and confidentiality as barriers as well as reporting five or more barriers. The vast majority (88.3\%) of youth who identified as American Indian/Alaska Native also identified as Hispanic and/or multiple races. For this reason, we conducted an additional analysis in which any youth who identified as American Indian/Alaska Native $(n=1,135)$ was coded as such, regardless of any other identification. Most results for the subsequent logistic regression were unaffected, except that this more inclusively-defined group of American Indian/Alaska Native youth had 0.820.83 times the odds of perceiving confidentiality and discomfort talking with staff as barriers than Hispanic youth.

Compared to the reference group of youth living in stable housing, youth living in juvenile justice facilities had 0.42-0.58 times the odds of perceiving cost and confidentiality as barriers, as well as reporting five or more barriers. The only statistically significant difference for youth in other living situations was youth in foster care had 1.27 times the odds of perceiving test results as a barrier and unstably housed youth had 1.41 times the odds of perceiving cost as a barrier. Youth with sexual experience had 0.78-0.80 times the odds of perceiving cost as a barrier, as well as reporting five or more barriers. 
The pattern of results was similar for the four barriers reported by fewer than half of adolescents (see Supplemental Table 1). The odds of reporting concerns about judgment by staff and lack of access were significantly higher for females and for youth identifying as transgender/non-binary/multiple genders than for males. When controlling for all other participant characteristics, increasing age was associated with decreased odds of perceiving each of these four barriers. The odds of reporting concerns about judgment by staff and lack of access were higher for LGBQ+ youth than for heterosexual youth. Compared to Hispanic youth, Asian or Pacific Islander/Native Hawaiian youth had the highest odds of reporting discomfort talking with staff, judgment by staff, and lack of knowledge about the visit as barriers. In contrast, Black youth had lower odds of reporting judgment by staff and lack of access as barriers. Living in a juvenile justice setting was associated with lower odds of reporting judgment by staff and lack of access as barriers. Sexual experience was associated with lower odds of reporting discomfort talking with staff and lack of knowledge about the visit as barriers.

\section{Discussion}

This study found that concerns about test results, cost of services, and confidentiality were the most common barriers to SRH services perceived by adolescents prior to participating in a sexual health education program in California. Across these barriers, younger adolescents consistently reported greater perceived barriers, even after controlling for sexual experience and other variables. Early adolescence represents a critical developmental stage that requires support in cultivating autonomy and decision-making skills, particularly around SRH issues [35, 36]. Similarly, when assessing the burden of five or more barriers, females, younger adolescents, LGBTQ+ youth, and Asian or Pacific Islander/Native Hawaiian youth all had greater odds of reporting five or more barriers, indicating that some groups may face a higher overall burden to access. Differing from previous research, after controlling for other characteristics, Black youth had lower odds of reporting many of the barriers, as well as of reporting five or more barriers [12, 13,33].

Consistent with Penchansky and Thomas's dimensions of access to health care, about half of the respondents were concerned about cost, test results, and confidentiality, which align with the affordability and accommodation dimensions in the original theory, while accessibility was a concern to about a quarter of the respondents. Our results show that lack of knowledge of what to expect in a clinic visit was a barrier to over a quarter of youth (29.1\%). Although the original theory did not mention awareness as a dimension, subsequent research has recommended this addition [32], which is supported by our results.

These results highlight the need to address disparities among certain groups of adolescents. For example, youth in foster care, who are much more likely to experience pregnancy in adolescence, may face the additional barrier of judgmental guardians and require policies and trauma-informed programs tailored to their needs [37]. In contrast, youth in juvenile justice facilities generally reported lower barriers to services, which may reflect on-site access to SRH care [33]. In addition, sexual health education and clinical services need to be responsive to and inclusive of diverse genders and sexual orientations. Differences by race and ethnicity also show the need for programs and services that are culturally appropriate. The higher perceived barriers among youth identifying as Asian or Pacific Islander/Native Hawaiian require efforts to address stigma and confidentiality concerns in these communities [16].

These results also highlight quantitatively the burden of multiple barriers to SRH care for adolescents. Previous qualitative research with adult women seeking abortions suggests that the effects of barriers are cumulative, with women who simultaneously face multiple barriers experiencing worse outcomes [21]. Other qualitative research suggests that the problem of multiple barriers may be compounded for youth from marginalized groups, who are more likely to forgo care when they face discriminatory treatment in the healthcare system on top of barriers unrelated to discrimination [38]. Thus, to reduce disparities in health outcomes, it is vital to improve access for vulnerable groups that may face a greater burden of barriers [22].

While this study focused on barriers to access, other research has identified enablers or facilitators that increase the likelihood that adolescents will seek services. Parental communication about SRH, social norms, and individual motivation are all potential facilitators $[39,40]$. Providing more information to adolescents about available services can increase awareness and may alleviate concerns about certain barriers. One potential avenue for this information is through sexual health education in schools and other settings. CA PREP requires all agencies implementing sexual health education to provide information about local SRH services [41]. Sexual health education programs can directly address adolescents' questions and concerns, such as discussing practices to ensure privacy and confidentiality in clinics, as well as providing local clinic information including available services, hours, location, and cost [42]. Schools may also consider developing formal referral systems to SRH services or providing contraception at school-based health centers $[43,44]$. 
Clinics also must better address youth concerns. Previous studies of youth-friendly services have identified the importance of ensuring confidentiality, respectful interactions with providers and other staff, specialized provider training, and addressing other logistical barriers such as insurance and cost $[45,46]$. Programs and policies should also consider broader structural and social determinants of health, such as educational and employment opportunities, which may affect adolescents' need for and access to services.

\section{Limitations}

Although CA PREP prioritizes services in low-income communities, this study did not assess other social determinants of health, including household socioeconomic status, insurance status, and geographic location, which other studies have shown to be associated with access to care as well as other adolescent health outcomes [17, 47]. Because the study was based in California, which mandates sexual health education and confidential access to care for minors, these results may underestimate the access barriers that youth face in other states. Some barriers may have been interpreted differently by respondents. For example, the question on confidentiality did not distinguish between privacy concerns with peers and confidentiality concerns with parents. Similarly, worry about test results may be interpreted as worry about what would happen if a test is positive or how this information is communicated.

Traditional measures of race and ethnicity do not align with many respondents' self-identification, particularly those who identify as Hispanic or Latino. To avoid losing over 4,500 Hispanic youth in multivariate analyses due to missing race, we aggregated race and ethnicity. However, this meant that the $40.9 \%$ of youth who did report a race in addition to their Hispanic ethnicity were not represented in the racial categories. Follow-up analyses indicated that this did not seriously affect results for American Indian/Alaska Native youth, the group most affected by this aggregation.

\section{Conclusion}

The majority of adolescents participating in sexual and reproductive health education programs face barriers to accessing appropriate SRH services, with youth in certain demographic groups including younger adolescents, youth identifying as transgender/non-binary/ multiple genders, LGBQ+ youth, and Asian or Pacific Islander/Native Hawaiian youth more likely than other youth to report barriers. Access can be improved through strengthening linkages between clinics and sexual health education programs, providing youth-friendly clinical services, and ensuring youth have sufficient information, skills and support to access care.

\begin{abstract}
Abbreviations
CA: California; CDPH: California Department of Public Health; HIV: Human immunodeficiency virus; MCAH: Maternal, Child and Adolescent Health; LGBQ+: Lesbian, gay, bisexual, queer, and other sexual orientations; LGBTQ: Lesbian, gay, bisexual, transgender, and queer; OR: Odds ratio; PREP: Personal Responsibility Education Program; SRH: Sexual and reproductive health; STI: Sexually transmitted infection.
\end{abstract}

\section{Supplementary Information}

The online version contains supplementary material available at https://doi. org/10.1186/s12913-021-07278-3.

Additional file 1: Supplemental Table 1. Predictors of perceiving other barriers to SRH services

\section{Acknowledgements}

This work was supported by funding from the California Department of Public Health, Maternal, Child and Adolescent Health Division (CDPH-MCAH) under contract \#18-10026. The authors are grateful to the Bixby Center for Global Reproductive Health and Cynthia Harper for their thoughtful review and to Nancy Hills for statistical consultation.

\section{Authors' contributions}

MJD, TVA, CGZ, and MS contributed to the conception and design of the study, as well as review and revision of the manuscript. MJD wrote the first version of the introduction and discussion. TVA completed data collection, conducted data analysis, and wrote the first version of the methods and results sections. CGZ completed data collection and conducted data analysis. AMB substantially revised the manuscript. CB contributed to the conception of the study. MS conducted data analysis. MJD, TVA, CGZ, AMB, CB, and MS read and approved the final manuscript.

\section{Funding}

The study design, data collection and data analyses were completed under contract \#18-10026 with the California Department of Public of Health. CDPHMCAH has funding for the CA Personal Responsibility Education Program through the U.S. Department of Health and Human Services, Administration for Children and Families, Family and Youth Services Bureau. The findings and conclusions in this study are those of the authors and do not necessarily represent the views of the California Department of Public Health, or the U.S. Department of Health and Human Services.

\section{Availability of data and materials}

The dataset analyzed for the current study is not publicly available due to California state data regulations and concerns about confidentiality for study participants. However, the dataset is available from the authors upon reasonable request and subject to the approval of the California Department of Public Health - Maternal, Child and Adolescent Division.

\section{Declarations}

\section{Ethics approval and consent to participate}

This study was approved by the Committee for the Protection of Human Subjects [12-08-0658] of the California Health and Human Services Agency. All study procedures were conducted in accordance with the World Medical Association's Helsinki Declaration for Human Studies. Informed assent was obtained from all participants in the study. In addition, passive informed consent from parents or guardians was solicited for those aged less than 18 years.

Consent for publication

Not applicable. 


\section{Competing interests}

The authors declare that they have no competing interests.

\section{Author details}

${ }^{1}$ Department of Epidemiology and Biostatistics, University of California, San Francisco, San Francisco, CA, USA. ${ }^{2}$ Philip R. Lee Institute for Health Policy Studies, University of California, San Francisco, 490 Illinois St, San Francisco, CA 94107, USA. ${ }^{3}$ Bixby Center for Global Reproductive Health, University of California, San Francisco, San Francisco, CA, USA. ${ }^{4}$ California Department of Public Health, Maternal, Child and Adolescent Health Division, 1615 Capitol Ave, MS 8300, P.O. Box 997420, Sacramento, CA 95899-7420, USA

Received: 22 June 2021 Accepted: 9 November 2021

Published online: 22 November 2021

\section{References}

1. Miller MK, Wickliffe J, Jahnke S, Linebarger JS, Dowd D. Accessing general and sexual healthcare: experiences of urban youth. Vulnerable Child Youth Stud. 2014;9(3):279-90.

2. Coker TR, Sareen HG, Chung PJ, Kennedy DP, Weidmer BA, Schuster MA. Improving access to and utilization of adolescent preventive health care: the perspectives of adolescents and parents. J Adolesc Health 2010;47(2):133-42.

3. Carroll C, Lloyd-Jones M, Cooke J, Owen J. Reasons for the use and non-use of school sexual health services: a systematic review of young people's views. J Public Health. 2012;34(3):403-10.

4. Johnson KM, Dodge LE, Hacker MR, Ricciotti HA. Perspectives on family planning services among adolescents at a Boston community health center. J Pediatr Adolesc Gynecol. 2015:28(2):84-90.

5. Fox HB, Philliber SG, McManus MA, Yurkiewicz SM. Adolescents' experiences and views on health care. Washington D.C.: The National Alliance to Advance Adolescent Health; 2010. p. 1-14.

6. Fuentes $\mathrm{L}$, Ingerick M, Jones $\mathrm{R}$, Lindberg L. Adolescents' and young adults' reports of barriers to confidential health care and receipt of contraceptive services. J Adolesc Health. 2018;62(1):36-43.

7. Marcell AV, Morgan AR, Sanders R, Lunardi N, Pilgrim NA, Jennings JM, et al. The socioecology of sexual and reproductive health care use among young urban minority males. J Adolesc Health. 2017:1-9.

8. Macapagal K, Bhatia R, Greene GJ. Differences in healthcare access, use, and experiences within a community sample of racially diverse lesbian, gay, bisexual, transgender, and questioning emerging adults. LGBT Health. 2016:3(6):434-42.

9. Hoffman ND, Freeman K, Swann S. Healthcare preferences of lesbian, gay, bisexual, transgender, and questioning youth. J Adolesc Health. 2009;45:222-9.

10. Charlton BM, Corliss HL, Missmer SA, Frazier L, Rosario M, Kahn JA, et al. Reproductive health screening disparities and sexual orientation in a cohort study of U.S. adolescent and young adult females. J Adolesc Health. 2011;49:505-10

11. Paschen-Wolff MM, Kelvin EA, Wells BE, Grov C. Sexual orientation and pregnancy among adolescent women in the National Survey of Family Growth, 2002-2015. LGBT Health. 2018;5(8):449-60.

12. Galloway CT, Duffy JL, Dixon RP, Fuller TR. Exploring African-American and Latino teens' perceptions of contraception and access to reproductive health care services. J Adolesc Health. 2017:60(3S):S57-62.

13. Rosenthal L, Lobel M. Gendered racism and the sexual and reproductive health of Black and Latina Women. Ethn Health. 2020;25(3):367-92.

14. Morales-Aleman MM, Ferreti G, Scarinci IC. "I don't like being stereotyped, I decided I was never going back to the doctor": Sexual healthcare access among young Latina women in Alabama. J Immigr Minor Health. 2019.

15. Cahn MA, Harvey SM, Gonzales K. Use of sexual health services among American Indian and Alaska Native women. Women Health. 2019;59(9):953-66.

16. Frost M, Cares A, Gelman K, Beam R. Accessing sexual and reproductive health care and information: Perspectives and recommendations from young Asian American women. Sex Reprod Healthc. 2016;10:9-13.

17. Barral RL, Cartujano B, Perales J, Ramirez M, Cowden JD, Trent ME, et al. Knowledge, beliefs, and attitudes about contraception among rural Latino adolescents and young adults. J Rural Health. 2020;36(1):38-47.
18. Chelvakumar G, Ford N, Kapa HM, Lange HLH, McRee AL, Bonny AE. Healthcare barriers and utilization among adolescents and young adults accessing services for homeless and runaway youth. J Community Health. 2017;42(3):437-43.

19. Hudson AL. Where do youth in foster care receive information about preventing unplanned pregnancy and sexually transmitted infections. J Pediatr Nurs. 2012;27(5):443-50.

20. Penchansky R, Thomas JW. The concept of access: definition and relationship to consumer satisfaction. Med Care. 1981;19(2):127-40.

21. Jerman J, Frohwirth L, Kavanaugh ML, Blades N. Barriers to abortion care and their consequences for patients traveling for services: qualitative findings from two states. Perspect Sex Reprod Health. 2017;49(2):95-102.

22. Corscadden L, Levesque JF, Lewis V, Strumpf E, Breton M, Russell G. Factors associated with multiple barriers to access to primary care: an international analysis. Int J Equity Health. 2018;17(1):28.

23. Kumar N, Brown JD. Access barriers to long-acting reversible contraceptives for adolescents. J Adolesc Health. 2016;59(3):248-53.

24. Chandra-Mouli V, McCarraher DR, Phillips SJ, Williamson NE, Hainsworth G. Contraception for adolescents in low and middle income countries: needs, barriers, and access. Reprod Health. 2014;11(1):1.

25. Bender SS, Fulbright YK. Content analysis: a review of perceived barriers to sexual and reproductive health services by young people. Eur J Contracept Reprod Health Care. 2013;18(3):159-67.

26. Marmot M, Friel S, Bell R, Houweling TA, Taylor S. Commission on social determinants of $\mathrm{H}$ : closing the gap in a generation: health equity through action on the social determinants of health. Lancet. 2008;372(9650):1661-9.

27. California Healthy Youth Act. Pupil instruction: sexual health education. In.; 2015.

28. Teen Pregnancy Prevention Resource Center. Evidence-based programs [http://www.hhs.gov/ash/oah/oah-initiatives/teen_pregnancy/db/tppsearchable.html]

29. California Department of Public Health: 2014 California Adolescent Sexual Health Needs Index (CASHNI). In. Sacramento, CA: Department of Public Health, Maternal, Child and Adolescent Health Program; 2016.

30. Fingertip Facts on Education in California [https://www.cde.ca.gov/ds/ ad/ceffingertipfacts.asp]

31. McLaughlin CG, Wyszewianski L. Access to care: remembering old lessons. Health Serv Res. 2002;37(6):1441-3.

32. Saurman E. Improving access: modifying Penchansky and Thomas's Theory of Access. J Health Serv Res Policy. 2016;21(1):36-9.

33. Suresh SC, Questell L, Sufrin C. Access to reproductive health care in juvenile justice facilities. J Pediatr Adolesc Gynecol. 2020;33(3):296-301.

34. Theobald E. Students are rarely independent: When, why, and how to use random effects in discipline-based education research. Cbe-Life Sci Educ. 2018;17(3).

35. Blum RW, Astone NM, Decker MR, Mouli VC. A conceptual framework for early adolescence: a platform for research. Int J Adolesc Med Health. 2014:26(3):321-31.

36. Igras SM, Macieira M, Murphy E, Lundgren R. Investing in very young adolescents' sexual and reproductive health. Glob Public Health. 2014;9(5):555-69.

37. King B, Van Wert M. Predictors of early childbirth among female adolescents in foster care. J Adolesc Health. 2017;61(2):226-32.

38. Robards F, Kang M, Steinbeck K, Hawke C, Jan S, Sanci L, et al. Health care equity and access for marginalised young people: a longitudinal qualitative study exploring health system navigation in Australia. Int J Equity Health. 2019;18(1):41

39. Haley T, Puskar K, Terhorst L, Terry MA, Charron-Prochownik D. Condom use among sexually active rural high school adolescents: personal, environmental, and behavioral predictors. J Sch Nurs. 2013;29(3):212-24.

40. Hall KS, Moreau C, Trussell J. Associations between sexual and reproductive health communication and health service use among U.S. adolescent women. Perspect Sex Reprod Health. 2012;44(1):6-12.

41. California Department of Public Health, University of California San Francsico: Adolescent sexual health education programs: access to clinical sexual and reproductive health services In.: Maternal, Child and adolescent health division; 2020.

42. Decker MJ, Dandekar S, Gutmann-Gonzalez A, Brindis CD. Bridging the gap between sexual health education and clinical services: adolescent perspectives and recommendations. J Sch Health. 2021. 
43. Leung E, Wanner KJ, Senter L, Brown A, Middleton D. What will it take? Using an implementation research framework to identify facilitators and barriers in implementing a school-based referral system for sexual health services. BMC Health Serv Res. 2020;20(1):292.

44. Love HE, Schlitt J, Soleimanpour S, Panchal N, Behr C. Twenty years of school-based health care growth and expansion. Health Aff. 2019;38(5):755-64.

45. Romero LM, Olaiya O, Hallum-Montes R, Varanasi B, Mueller T, House $L D$, et al. Efforts to increase implementation of evidence-based clinical practices to improve adolescent-friendly reproductive health services. J Adolesc Health. 2017;60(3S):S30-7.
46. Brittain AW, Loyola Briceno AC, Pazol K, Zapata LB, Decker E, Rollison JM, et al. Youth-friendly family planning services for young people: A systematic review update. Am J Prev Med. 2018;55(5):725-35.

47. Viner RM, Ozer EM, Denny S, Marmot M, Resnick M, Fatusi A, et al. Adolescence and the social determinants of health. Lancet. 2012;379(9826):1641-52.

\section{Publisher's Note}

Springer Nature remains neutral with regard to jurisdictional claims in published maps and institutional affiliations.
Ready to submit your research? Choose BMC and benefit from:

- fast, convenient online submission

- thorough peer review by experienced researchers in your field

- rapid publication on acceptance

- support for research data, including large and complex data types

- gold Open Access which fosters wider collaboration and increased citations

- maximum visibility for your research: over $100 \mathrm{M}$ website views per year

At BMC, research is always in progress.

Learn more biomedcentral.com/submissions 